\title{
An assessment of trends in the use of the IUD in Ghana
}

John Gyapong

Gifty Addico

Ivy Osei

Mercy Abbey

Dominic Atweam Kobinah

See next page for additional authors

Follow this and additional works at: https://knowledgecommons.popcouncil.org/departments_sbsr-rh

Part of the Demography, Population, and Ecology Commons, International Public Health Commons, and the Women's Health Commons

How does access to this work benefit you? Let us know!

\section{Recommended Citation}

Gyapong, John, Gifty Addico, Ivy Osei, Mercy Abbey, Dominic Atweam Kobinah, Henrietta Odoi-Agyarko, Gloria Quansah Asare, Harriet Birungi, and lan Askew. 2003. "An assessment of trends in the use of the IUD in Ghana," FRONTIERS Final Report. Washington, DC: Population Council. 


\section{Authors}

John Gyapong, Gifty Addico, Ivy Osei, Mercy Abbey, Dominic Atweam Kobinah, Henrietta Odoi-Agyarko, Gloria Quansah Asare, Harriet Birungi, and lan Askew 


\section{An Assessment of Trends in the Use of the IUD in Ghana}

May 2003

This study was funded by the UNITED STATES AGENCY FOR INTERNATIONAL DEVELOPMENT (USAID) under the terms of Cooperative Agreement Number HRN-A-00-98-00012-00 and Population Council Subagreement Number AI02.06A. The opinions expressed herein are those of the authors and do not necessarily reflect the views of USAID. 


\title{
Contributors
}

\author{
Health Research Unit, Ghana Health Service \\ John Gyapong \\ Gifty Addico \\ Ivy Osei \\ Mercy Abbey \\ Dominic Atweam Kobinah
}

Reproductive Health Unit, Ghana Health Service

Henrietta Odoi Agyarko

Gloria Quansah Asare

Frontiers in Reproductive Health Program, Population Council

Harriet Birungi

Ian Askew 


\section{Table Of Contents}

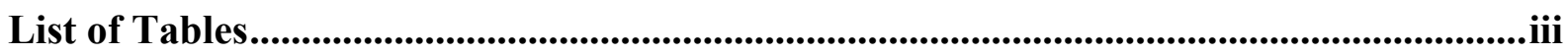

List of Acronyms ................................................................................................................................ iv

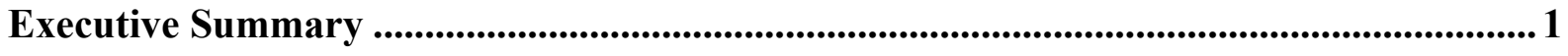

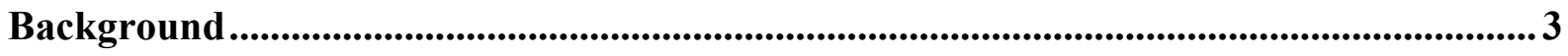

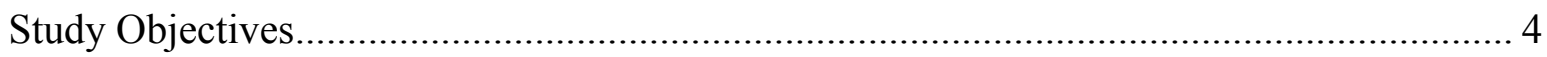

Research Methodology .......................................................................................................................5

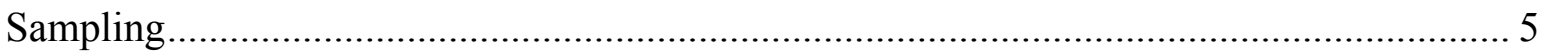

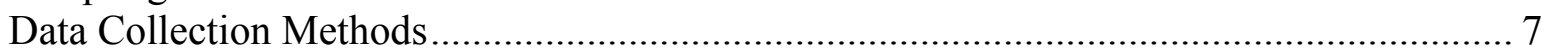

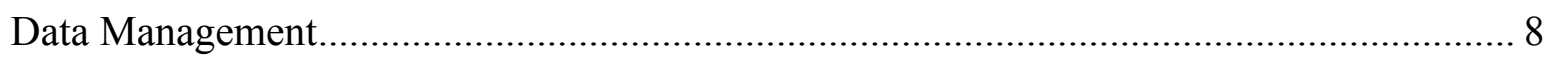

Findings .......................................................................................................................................... 10

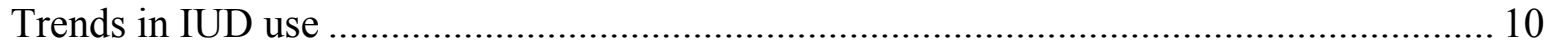

Knowledge, Perceptions and Practices........................................................................... 11

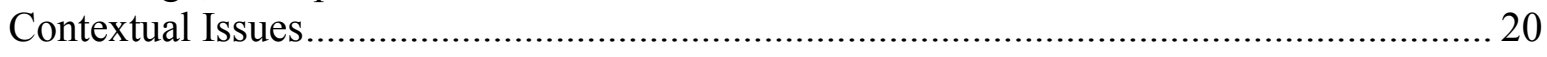

Discussion ....................................................................................................................................... 23

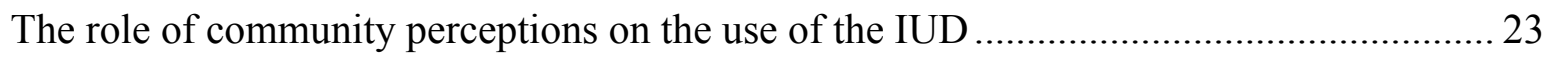



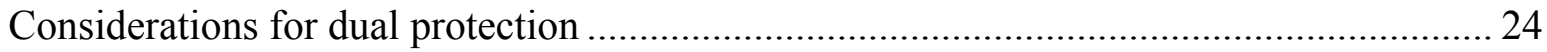

Service Delivery System Barriers ………………………….......................................... 24

Conclusions and Recommendations ..............................................................................................2

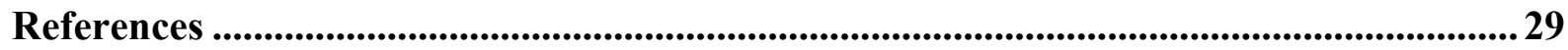




\section{List of Tables}

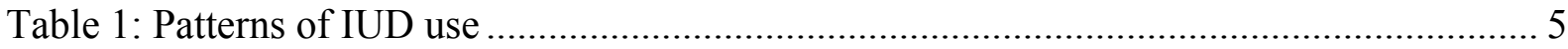



Table 3: Institutions interviewed at the national level....................................

Table 4: Simulated Clients profile............................................................................. 8

Table 5: Summary findings of secondary analysis of GDHS: $1988,1993,1998 \ldots \ldots \ldots \ldots \ldots 10$

Table 6: Percentage of preferred method for non-users of FP ............................................. 10

Table 7: Percentage of FP acceptors at GHS clinics and other service delivery points ........... 11

Table 8: A Comparison of NRHSP on eligibility for the IUD and providers' views .............. 15

Table 9: Family Planning Training Institutions in Ghana - Activities and Focus ................... 20 


\section{List of Acronyms}

\begin{tabular}{|c|c|}
\hline AIDS & Acquired Immune Deficiency Syndrome \\
\hline FGD & Focus Group Discussion \\
\hline FP & Family Planning \\
\hline GDHS & Ghana Demographic And Health Survey \\
\hline GHS & Ghana Health Service \\
\hline GRMA & Ghana Registered Midwives Association \\
\hline GSA & Ghana Situation Analysis \\
\hline GSMF & Ghana Social Marketing Foundation \\
\hline HIV & Human Immunodeficiency Virus \\
\hline HRU & Health Research Unit \\
\hline IEC & Information, Education and Communication \\
\hline IUD & Intra-Uterine contraceptive Device \\
\hline NTC & Nurses Training College \\
\hline PHNS & Public Health Nurses School \\
\hline PID & Pelvic Inflammatory Diseases \\
\hline PPAG & Planned Parenthood Association of Ghana \\
\hline $\mathrm{RCH}$ & Reproductive and Child Health \\
\hline $\mathrm{SC}$ & Simulated Client \\
\hline SDP & Service delivery point \\
\hline SM & Safe Motherhood \\
\hline STD & Sexually Transmitted Disease \\
\hline STI & Sexually Transmitted Infections \\
\hline WHO & World Health Organization \\
\hline
\end{tabular}




\section{Executive Summary}

The IUD is a safe and reversible method, which requires little effort on the part of the user once inserted and offers 10 years of protection against pregnancy. In spite of these advantages, the use of the IUD in relation to other contraceptive methods is reported to have either stagnated or declined in a number of countries including Ghana. Given the lack of understanding of the reasons why IUD use in Ghana has stagnated and may well have declined, this study addressed the following key questions:

- What client characteristics affect the demand for and use of the IUD?

- What are the provider and system characteristics that shape use of the IUD?

- What can be done to reduce barriers to the use of the IUD?

The overall aim of the study was to inform the Ghana Health Service, USAID and other partners on future directions for contraceptive promotion and supply.

The study was descriptive involving both quantitative and qualitative methods of data collection. The study covered a period of nine months, March - November 2002. The first part of the study was a secondary analysis of data from the Ghana Demographic and Health Survey (GDHS) 1988,1993 and 1998, Ghana Situation Analysis (GSA) and existing service statistics, to explore trends in the use of the IUD. The second component of the study collected qualitative data using a combination of in-depth interviews, focus group discussions (FGD) and simulated client (SC) surveys in three regions, namely Greater Accra, Eastern and Volta. These regions were selected on the basis of trends (increasing, decreasing and non-use) in the proportion of married women currently using contraceptives that are using the IUD.

Over the period 1988 - 1998, knowledge about the IUD has been relatively high. However, a very low percentage of women contraceptive users report ever using the IUD. Similarly, data on current use during the survey (GDHS) period shows stagnation of the IUD compared to other methods. Reasons for discontinuation of use varied by contraceptive method. Overall, side effects were cited as the major reason for discontinuing the IUD compared to other methods.

The stagnating demand for the IUD as a family planning method can be attributed to several factors, including perceptions and rumours about the method. The design of the IUD and fear of weight loss associated with its use also discourages potential acceptors. Other barriers impeding IUD use are insufficient promotion of the product (i.e. poor demand creation) and insufficient number of providers with practical experience.

Contrary to the general belief that providers' bias against the product may contribute to the decline in use of the IUD, the findings show that in general, providers have a favourable attitude towards the product. 
The study recommends that:

- Marketing of the IUD should be intensified through the Ghana Life Choices Program, using multiple strategies including branding of the product, and the testimonies of satisfied clients to dispel rumours and demystify the product;

- There is a need for IUD-focused training and for the creation of a critical mass of trained IUD providers;

- The MOH should review the National Reproductive Health Service Protocols on who qualifies to insert the IUD, and also to clarify the eligibility criteria with regard to nulliparous and HIV infected clients;

- There is a need to address issues related to cost. Clients should be informed about the ease and cost effectiveness of using the IUD; that it is a one-visit only method (plus check-up) in contrast with injections or pill that require routine visits. 


\section{Background}

The IUD is a safe and reversible method, which requires little effort on the part of the user once inserted and offers 10 years of protection against pregnancy. In spite of these advantages, family planning clients can be reluctant to use the IUD and health workers can be reluctant to provide it. In a number of countries, including Ghana, the use of the IUD in relation to other contraceptive methods is reported to have either stagnated or declined (e.g. Costello 1998; GDHS 1998). For instance, the use of the IUD among married women declined in Indonesia from 13 percent in 1991 to 10 percent in 1994 (Hoesni et al. 1995). In Kenya, IUD use dropped from 31 percent among modern method users in 1984 to 15 percent in 1993 (Stanback et al. 1995). In Guatemala, IUD use has remained stable at around 2 percent despite an overall increase in contraceptive prevalence from 23 percent in 1987 to 38 percent among women in union in 1998/99 (Brambila 2001). In Ghana, national estimates from the Ghana Demographic Health Survey (GDHS) indicate that modern contraceptive prevalence doubled from 5 percent in 1988 to 10 percent in 1993, and increased to 13 percent in 1998. A steady increase in the use of the pill, injectables and condoms has been observed. However, use of the IUD has remained stagnant at one percent over a period of 10 years (GDHS 1998).

Overall, couples' knowledge of family planning methods is high (89\%) in Ghana, but varies by type of method. Only 35.5 percent of the couples had ever heard about the IUD (1998 GDHS). The IUD is readily available through the Ghana Health Service (GHS), Ghana Social Marketing Foundation (GSMF), Ghana Registered Midwives Association (GRMA), and Planned Parenthood Association of Ghana (PPAG) clinics. However, recent service statistics drawn from these sources show a 40 percent decline in the provision of the IUD from 25,000 acceptors in 1995 to only 10,000 in 2000. Yet the Ghana Situation Analysis study shows convincingly that the IUD, and its insertion equipment, are available at most family planning service delivery points (Ghana Statistical Service 1997). Also, information exchange on the IUD takes place in almost three-quarters of provider-client interactions, and yet this does not seem to translate into increased demand for the method (Ghana Statistical Service 1997). Country specific reasons for the stagnating or declining use of the IUD are still unclear.

A study among IUD acceptors in Indonesia points out that changes in the use of the IUD over time have been caused by a variety of factors including availability of methods, availability of medical facilities and skilled personnel, campaigns to promote specific methods, medical barriers, side effects, management of side effects and changes in user preferences (Hoesni et al. 1995). With respect to side effects and health concerns, some studies show that use of the IUD is significantly associated with Reproductive Tract Infections (Bhatia and Cleland 1995). Indeed, the World Health Organization's (WHO) medical eligibility criteria for safe use of contraceptives state that current sexually transmitted infection (STI) contraindicates IUD use, as does any previous STI that has not been cured for at least three months (World Health Organization 1996). The guidelines also emphasize that insertion of the IUD in an HIV-infected woman or one who is at high risk of infection is not usually recommended.

Safety concerns for HIV-positive women using IUDs include the fear that a woman's immune system may be weakened and unable to fight off infections, such as another STI that could lead to 
pelvic inflammatory disease (PID). Findings from a recent study in Kenya, however, raised questions about the WHO guidelines. The study found that $156 \mathrm{HIV}$-infected women, including those whose immune systems were suppressed at the time of the IUD insertion, had no more overall complications (i.e. PID, removal due to pain, bleeding or pain, expulsion or pregnancy) following insertion than did the 493 uninfected women (Sinei et al 1998).

Regardless of such findings, in certain settings these guidelines seem to have decreased demand for the IUD as well as brought about discontinuation among existing acceptors. In the Philippines, side effects and/or health concerns were the most commonly cited reason for discontinuing use of the IUD. Program statistics show that 22 percent of IUD users discontinued use within a year of adoption because of side effects and health concerns (Costello 1998). A study in Kenya identified five interrelated factors for the declining trend in the use of the IUD: fear of HIV acquisition/transmission, poor quality of care, poor product image, and provider bias or preference, and changing client method preferences (Stanback et al 1995).

At the program level, the critical question for understanding the determinants of contraceptive method choice is whether use of a method is predominantly provider or client driven (Stanback et al 1995; Magadi et al 2001). Provider driven practices include the provider favouring some methods and discouraging others in the absence of sound medical rationale, as well as failing to ascertain and consider the preferences of the client (Speizer et al 1998). In an on-going study to assess the declining use of the IUD in Guatemala, Brambila (2001) argues that such problems possibly originate from the lack of IUD training among service providers, who may not feel confident to offer the service to potentially interested women, or, based on personal experiences, providers might have personal preferences. Providers might simply have a generalized negative feeling towards the IUD. On the other hand, method choice is also substantially affected by client or individual's fears of health side effects, whether these are real or based on unfounded rumours (Ngom 1994; Rutenberg \& Watkins 1997).

Given the lack of understanding of the reasons why IUD use in Ghana has stagnated and may well have declined, the study addressed the following key questions:

- What client characteristics affect the demand for and use of the IUD?

- What are the provider and system characteristics that shape use of the IUD?

- What can be done to reduce barriers to the use of the IUD?

\section{Study Objectives}

The overall aim of the study was to inform the Ghana Health Service, USAID and other partners on future directions for contraceptive promotion and supply.

The immediate objectives included:

- To examine the determinants and switching pattern/behaviour of IUD users;

- To assess the role of socio-cultural perceptions and misperceptions on the use of the IUD; 
- To assess providers' and clients' attitudes towards the use of the IUD;

- To assess the content and quality of information exchange between the provider and client on the IUD;

- To identify provider and other system barriers including pre-service and in-service training, logistics, supply and cost issues that may restrict clients' access to the IUD; and

- To identify policy and program implications for the revitalization, if necessary, of IUD use in Ghana.

\section{Research Methodology}

This was an in-depth assessment involving both quantitative and qualitative methods of data collection. The first part of the study was a secondary analysis of data from the GDHS, and existing service statistics, to explore trends in the use of the IUD. The second component of the study involved the collection of qualitative data through in-depth interviews, focus group discussions and the use of simulated clients.

\section{Sampling}

The ten regions in the country were first grouped according to the patterns of IUD use (Table 1). Three regions (Greater Accra, Eastern and Volta) were selected on the basis of trends (increasing, decreasing and non-use) in the proportion of married women currently using contraceptives that are using the IUD.

Table 1: Patterns of IUD use

\begin{tabular}{|l|c|c|c|c|}
\hline Regional trends of & \multirow{2}{*}{$\begin{array}{c}\text { CPR } \\
\text { IUD Use }\end{array}$} & \multicolumn{3}{|c|}{ IUD Use } \\
\cline { 3 - 5 } & $\mathbf{1 9 9 8}$ & $\mathbf{1 9 8 8}$ & $\mathbf{1 9 9 3}$ & $\mathbf{1 9 9 8}$ \\
\hline Increasing trend & & & & \\
Greater Accra & 17.4 & 3.1 & 2.5 & 3.9 \\
Central Region & 13.1 & 0.3 & 1.3 & 1.8 \\
Brong Ahafo Region & 14.8 & 0.5 & 2.0 & 1.8 \\
Upper West & 9.1 & 0.1 & 0.0 & 1.0 \\
\hline Decreasing trend & & & & \\
Eastern region & 19.6 & 0.2 & 0.6 & 0.0 \\
Ashanti & 14.0 & 0.2 & 0.2 & 0.0 \\
Upper East & 7.5 & 0.1 & 0.8 & 0.3 \\
Northern & 5.6 & 0.0 & 0.3 & 0.3 \\
\hline Almost nil use of IUD & & \multicolumn{3}{|}{} \\
Volta region & 12.1 & 0.0 & 0.3 & 0.0 \\
Western region & 8.7 & 0.0 & 0.8 & 0.0 \\
\hline
\end{tabular}


Secondly, the region with the highest contraceptive prevalence level was purposively selected to maximize familiarity with the method, but also to understand factors that shape the fluctuation in the use patterns of the IUD particularly in the case of the Greater Accra Region. The study sites are summarized in Table 2.

Table 2: Study sites

\begin{tabular}{|c|c|c|c|c|}
\hline $\begin{array}{l}\text { Region } \\
(\mathrm{N}=3)\end{array}$ & $\begin{array}{l}\text { District } \\
(\mathrm{N}=6)\end{array}$ & $\begin{array}{l}\text { Sub-district } \\
(\mathrm{N}=12)\end{array}$ & $\begin{array}{l}\text { Public facility } \\
(\mathrm{N}=17)\end{array}$ & $\begin{array}{l}\text { Private facility } \\
(\mathrm{N}=6)\end{array}$ \\
\hline \multirow[t]{2}{*}{ Accra } & 1. Accra metro & $\begin{array}{l}\text { 1. Kpeshie } \\
\text { 2. Okai Koi }\end{array}$ & $\begin{array}{l}\text { La Polyclinic } \\
\text { Kaneshie Polyclinic } \\
\text { Achimota Hospital }\end{array}$ & $\begin{array}{l}\text { Mayfair Clinic \& } \\
\text { Maternity Home } \\
\text { (Laterbiokoshie) }\end{array}$ \\
\hline & $\begin{array}{l}\text { 2. Greater } \\
\text { Accra }\end{array}$ & $\begin{array}{l}\text { 3. Amasaman } \\
\text { 4. Madina }\end{array}$ & $\begin{array}{l}\text { Amasaman } \mathrm{HC} \\
\text { Madina } \mathrm{HC}\end{array}$ & Alpha Clinic (Madina) \\
\hline \multirow[t]{2}{*}{ Eastern } & 3. New Juaben & $\begin{array}{l}\text { 5. Koforidua } \\
\text { Municipal } \\
\text { 6. Oyoko }\end{array}$ & $\begin{array}{l}\text { Central Hospital MCH } \\
\text { Oyoko Health Post }\end{array}$ & $\begin{array}{l}\text { Koforidua Clinic } \\
\text { Pat's Maternity Home - } \\
\text { Koforidua }\end{array}$ \\
\hline & 4. Suhum & $\begin{array}{l}\text { 7. Suhum } \\
\text { 8. Asuboi }\end{array}$ & $\begin{array}{l}\text { Suhum Dist. Hospital } \\
\text { Suhum MCH } \\
\text { Asuboi HC }\end{array}$ & None \\
\hline \multirow[t]{2}{*}{ Volta } & 5. Ho & $\begin{array}{l}\text { 9. Adaklu } \\
\text { 10. Kpetoe }\end{array}$ & $\begin{array}{l}\text { Adaklu HC } \\
\text { Ho District Hospital } \\
\text { Kpetoe HC } \\
\end{array}$ & $\begin{array}{l}\text { Akpenamawu } \\
\text { Ho Clinic }\end{array}$ \\
\hline & 6. Hohoe & $\begin{array}{l}\text { 11. Akpafu } \\
\text { 12. Gbledi }\end{array}$ & $\begin{array}{l}\text { Hohoe District Hospital } \\
\text { Akpafu HC } \\
\text { Gbledi }\end{array}$ & $\begin{array}{l}\text { St.Michael's } \\
\text { Hohoe Clinic }\end{array}$ \\
\hline
\end{tabular}

Two districts (rural and urban) were randomly selected from each region, and then two subdistricts were randomly selected from each district, giving a total of 12 sub-districts. One government health facility in each sub-district and the district hospitals were included in the study. In addition, two private facilities were randomly selected from each region.

At least one family planning service provider from each of the selected service delivery points (SDP) was randomly selected and interviewed. A total of 35 providers were interviewed. The majority of the providers interviewed were midwives (26), with a few community health nurses (5) and medical officers (2). 


\section{Data Collection Methods}

\section{In-depth interviews}

In-depth interviews were conducted at both the national and regional levels, with the aim of exploring contextual and programmatic factors expected to influence provision of the IUD. At the national level, in-depth interviews were held with senior policy makers in the Reproductive and Child Health Unit of the Ghana Health Service and the National Population Council (NPC).

Key staff at IUD distributing sources in the country, IUD insertion training institutions, and USAID Collaborating Agencies were interviewed.

\section{Focus group discussions}

Focus group discussions (FGDs) were held in all three study regions to examine contraceptive choice determinants among potential family planning clients.

The IUD is a method that is normally recommended for spacing or limiting the number of pregnancies. Thus, in order to understand the demand factors for the IUD, the group discussions were arranged around three major strata:

- Women who are interested in having additional children but want to space them

- Women who want to stop having children

- Actual users to obtain their perspectives about the method.

However, the intended group discussion with actual users had to be cancelled due to difficulties in recruiting participants. Altogether, 12 group discussions were held in 6 urban and 6 rural communities in the three Regions. The communities were randomly selected from the catchment area of the facilities visited. The group participants were recruited from either the family planning clinics or the maternal and child health care clinics of the respective SDP. The participants of the focus group discussions were women aged 18-48 years who had at least one child. They were mostly Christians and had primary level education. All participants had lived in their communities for at least four years.

\section{Simulated clients}

Simulated clients (SC) were used to examine the provider knowledge and attitudes regarding the IUD and whether providers recommend the IUD to women who intend to delay, space or stop giving birth (see Huntington et al 1993). This component also investigated possible provider biases related to age, parity, and marital status (including type of marriage). The use of the SC method originates from a need to remain as unobtrusive as possible. Concurrence to undertake 
the study was sought from the Regional Directors of Health Services in the respective study regions.

The SCs were trained to assume specific roles during their visits. They were either adolescents or adult women who needed information about the most effective method for delaying, spacing or stopping birth. They were to request a contraceptive method they could use for a long time (at least two years), inform the provider that they are in a stable relationship and that, to the best of their knowledge, they had no sexually transmitted diseases. Since pregnancy contraindicates most methods, the SC was asked to tell the provider that she was in the fourth day of menstruation. The SC was instructed to specifically ask about the IUD if the provider did not volunteer information about it, to ensure that some information was exchanged about the method in each interaction. The profiles for the SCs are summarized in Table 4.

Table 4: Simulated Clients profile

\begin{tabular}{|l|r|}
\hline Clients & Client Profile \\
\hline Adolescent woman & $\begin{array}{r}\text { 1. Married nulliparous, interested in delaying first } \\
\text { birth }\end{array}$ \\
& $\begin{array}{l}\text { 2. } \begin{array}{l}\text { Unmarried nulliparous, interested in delaying } \\
\text { birth }\end{array} \\
\text { 3. } \begin{array}{l}\text { Married with at least one child, interested in } \\
\text { spacing }\end{array}\end{array}$ \\
\hline Adult woman & $\begin{array}{l}\text { 4. } \text { Married with at least one child, interested in } \\
\text { spacing }\end{array}$ \\
& $\begin{array}{l}\text { 5. In polygamous marriage, interested in spacing } \\
\text { 6. Unmarried, interested in spacing } \\
\text { 7. Multiparous, interested in stopping }\end{array}$ \\
\hline
\end{tabular}

Seven individuals, who represented each of these profiles, were recruited and trained. Each made one visit to the 23 selected SPDs using the same scenario for each visit. A total of $159 \mathrm{SC}$ visit were made. The visits were undertaken on separate days to minimize suspicion and/or potential bias.

The SCs were trained on the basis of a standardized scenario to ensure that they all could convincingly and accurately present it. They declined a pelvic exam, and when consultation progressed to the point of inserting the IUD, the SC indicated that she wanted to consult with her partner first, thanked the provider and left. A de-briefing interview was held between the SC and the Team Leader immediately after the clinic visit. The SC together with the team leader then completed a questionnaire.

\section{Data Management}

Data from the in-depth interviews with program managers and focus group discussions were transcribed from audiotapes by the interviewers. The research team then analyzed the transcripts, 
categorized responses by themes and wrote summaries. Data from the SCs visits and the provider interviews were coded, cleaned, entered and analyzed at the HRU using Epi Info data entry and analysis software. 


\section{Findings}

\section{Trends in IUD use}

The analysis (see Table 5) shows that over the period 1988 - 1998, women's knowledge about the IUD has been increasing, although it is relatively low in comparison to other modern methods. A very low proportion of women contraceptive users report ever using the IUD. Similarly, data on current use among all women shows a steady decline in the use of the IUD. Whereas the pill, injection and condoms have gained usage over the years, IUD use dropped from 4.0 percent in 1988 to 2.8 percent in 1998 ; illustrating a decline over a period of 11 years. This trend also applies to female sterilization.

Data on preferred method for non-users is included in Table 6 below. Here again, a low preference for the IUD over the period (1988, 1993, 1998) is shown. The future method of choice for non-users seems to be the injection, followed by the pill. There is also an intended preference for both the condom and Norplant.

Table 6: Percentage of preferred method for non-users of FP

\begin{tabular}{|l|c|c|c|}
\hline Year & $\mathbf{1 9 9 8}$ & $\mathbf{1 9 9 3}$ & $\mathbf{1 9 8 8}$ \\
\hline $\mathbf{N}$ & $\mathbf{1 , 8 7 2}$ & $\mathbf{1 , 8 5 5}$ & $\mathbf{1 , 3 3 4}$ \\
Pills & 19.6 & 21.9 & 23.4 \\
IUD & 2.4 & 2.9 & 2.5 \\
Injection & 36.1 & 28.5 & 19.1 \\
Norplant & 2.62 & 0.70 & - \\
Diaphragm & 0.9 & 2.3 & 1.5 \\
Condom & 6.3 & 5.9 & 1.1 \\
Female & 2.6 & 3.0 & 8.9 \\
Sterilization & & & \\
Male Sterilization & 0.0 & 0.1 & 0.1 \\
Periodic & 7.4 & 7.4 & 8.4 \\
Abstinence & & & \\
Withdrawal & 0.5 & 0.9 & 0.5 \\
Foaming Tablet & 2.6 & 0.7 & 0 \\
Other & 6.1 & 0.7 & 5.3 \\
Don't know & 0.4 & 0.0 & 1.8 \\
\hline
\end{tabular}

Table 5: Summary findings of secondary analysis of GDHS: 1988, 1993, 1998 (\%)

\begin{tabular}{|l|c|c|c|}
\hline Knowledge of Method & 1998 & 1993 & 1988 \\
\hline N (All women) & 4,843 & 4,562 & 4,488 \\
Any modern method & 92.5 & 90.6 & 73.8 \\
Condom & 86.8 & 79.5 & 48.5 \\
Pills & 78.4 & 79.4 & 59.7 \\
Injection & 77.6 & 74.8 & 42.6 \\
Female sterilization & 65.4 & 67.3 & 54.1 \\
Periodic abstinence & 59.4 & 57.1 & 39.0 \\
Withdrawal & 54.5 & 52.3 & 31.0 \\
IUD & 49.3 & 44.5 & 36.7 \\
Diaphragm & 42.0 & 53.5 & 36.6 \\
Male sterilization & 26.3 & 21.4 & 10.7 \\
Implant & 21.2 & 4.4 & - \\
\hline Ever used a method & 1998 & 1993 & 1988 \\
\hline N (All women) & 4,843 & 4,562 & 4,488 \\
Periodic abstinence & 20.4 & 16.4 & 18.3 \\
Withdrawal & 15.0 & 2.6 & 7.8 \\
Pill & 14.9 & 15.1 & 12.8 \\
Condom & 14.2 & 13.0 & 4.5 \\
Injection & 5.8 & 3.7 & 0.9 \\
Diaphragm & 5.1 & 8.8 & 7.9 \\
LAM & 3.4 & - & - \\
IUD & 1.9 & 2.2 & 1.2 \\
Female sterilization & 0.9 & 0.8 & 0.8 \\
Implant & 0.2 & 0.0 & - \\
Male sterilization & 0.0 & 0.0 & 0.0 \\
Others & 1.3 & 0.0 & 2.7 \\
\hline Current users & 1998 & 1993 & 1988 \\
\hline All women using & 872 & 862 & 552 \\
Periodic abstinence & 31.6 & 38.6 & 49.6 \\
Pill & 17.2 & 14.8 & 13.0 \\
Condom & 15.6 & 13.8 & 2.4 \\
Injectable & 12.3 & 6.4 & 1.6 \\
Withdrawal & 7.2 & 10.1 & 6.5 \\
Female sterilization & 5.1 & 4.1 & 7.3 \\
Diaphragm/Jelly/Foam & 3.9 & 5.8 & 9.8 \\
IUD & 2.8 & 3.7 & 4.0 \\
Other methods & 2.2 & 2.7 & 4.9 \\
LAM & 1.7 & - & - \\
Implant & 0.5 & 0.0 & - \\
Male sterilization & 0.0 & - & - \\
\hline
\end{tabular}


The 1993 GDHS covers a question on reasons for discontinuing a method. Overall, side effects were cited as the major reason for discontinuing use of the IUD. Among the 17 IUD users interviewed, nine had stopped use because of side effects. Other reasons given were desire for more children (4), religion (1), health concerns (1), infrequent sex (1), and not married (1).

Annual family planning records show a steady increase in the acceptance rates of the injectable at service delivery points and a declining trend for all other methods including the IUD (see Table 7).

Table 7: Percentage of FP acceptors at GHS clinics and other service delivery points

\begin{tabular}{|l|c|c|c|c|c|c|c|}
\hline Method & $\mathbf{1 9 9 5}$ & $\mathbf{1 9 9 6}$ & $\mathbf{1 9 9 7}$ & $\mathbf{1 9 9 8}$ & $\mathbf{1 9 9 9}$ & $\mathbf{2 0 0 0}$ & $\mathbf{2 0 0 1}$ \\
\hline IUD & 3.3 & 4.5 & 2.9 & 3.8 & 3 & 2.4 & 1.9 \\
\hline Combined Pill & 30 & 27 & 32 & 24.9 & 20 & 20.3 & 23.3 \\
\hline Mini Pill & 2.6 & 3.9 & 2.3 & 2.1 & 3 & 2.3 & 2 \\
\hline Male Condom & 20 & 15.3 & 12.6 & 9.5 & 12 & 13.4 & 11.1 \\
\hline Female Condom & - & - & - & - & - & - & 1.2 \\
\hline Injectable & 28 & 41.5 & 41.3 & 52.3 & 54 & 54.3 & 54.7 \\
\hline Foaming Tablets & 10 & 7 & 8.0 & 6 & 6 & 5.5 & 4.1 \\
\hline Female Sterilization & $<1$ & $<1$ & $<1$ & 0.5 & 0.6 & 0.2 & 0.2 \\
\hline Implant & - & 0.2 & 0.2 & 0.2 & 0.7 & 1.0 & 1.0 \\
\hline Male Sterilization & - & - & - & - & - & 0.4 & - \\
\hline Natural & $<1$ & 0.1 & 0.3 & 0.7 & 0.3 & 0.2 & 0.1 \\
\hline
\end{tabular}

Source: Annual Reports, Reproductive \& Child Health Unit, Ghana Health Service

Note: Availahle accentors data is incomnlete Therefore columns do not add un to $100 \%$

\section{Knowledge, Perceptions and Practices}

\section{Knowledge about the IUD}

The responses given by the various FGDs were quite similar. All participants had heard about family planning and could mention a few methods. The most frequently and spontaneously mentioned method was the injectable, followed by the pill and sometimes Norplant. The IUD was mentioned occasionally and usually required some prompting by the facilitators. Many of the participants had never seen the IUD, though they had heard about it. Those who had seen it said they saw it during 'weighing' at the Reproductive and Child Health (RCH) clinics. They described it as a metal thing or spring with strings attached to it. As one respondent stated: "It is like the hook they use to catch small fish." Others described it as 'a cross' and 'a needle.' One participant mentioned that the IUD is an object inserted at the entrance of the womb to prevent the entry of sperm. 


\section{Fears and Rumours about the IUD}

Most of the FGD participants had not ever used or seen the IUD. When shown a sample, they expressed some apprehension about how such an object could be inserted into one's body. Their responses repeatedly underlined their fears (see Box 1).

They speculated about the possible effects. They wondered whether such a thing would not destroy a man's genitals, cause sickness, slip inside one's body if not properly inserted, melt in the body, or irritate the partner's penis. The presence of the strings was also a cause for worry; as stated by one respondent: "I hate the strings."

\section{Box 1: Participants' Fears}

- "I am afraid because of the design."

- "The metal in the middle is scary."

- "It can hurt you."

- "It is like a broom, it can hurt you during sex."

- "It is a wire, maybe it will rust and destroy you...I think that is the cause of the bleeding."

Discussants worried about whether their husbands would not accidentally pull the strings during intercourse. The possibility that it could cause some discomfort for their spouses was mentioned frequently. Some respondents also said it could get pushed into the stomach by a long penis. Others felt the presence of the strings would make their partners suspect that they were up to something, specifically "Juju" - love medicine. As noted by one respondent: "As for the men, they are troublesome. Before you realize he has seen it, and will say you have done juju." Another added: "Indeed he will think it is medicine to make him love me more."

Discussions with providers also confirmed that clients present them with these fears. In their view, clients have many misconceptions about the IUD and its side effects. Clients believe that the IUD causes marital disharmony, abortion, that it can fail, and that it causes heavy bleeding, loss of weight and even death.

The study revealed several rumours surrounding the IUD. FGD participants mentioned that they had heard several things about the IUD. A participant narrated a story about a friend whose husband deserted her because he thought the IUD strings felt like a snake. The most frequently expressed rumour was that the IUD causes severe bleeding leading to excessive weight loss and ugliness, unlike the injectable which makes one bleed less, and therefore leads to weight gain and beauty. Instances were cited where friends who had used IUDs felt dizzy and collapsed. There was even one death cited. Other rumours stated are highlighted in Box 2. Simulated clients mentioned that providers were aware of these rumours and made attempts to dispel them during interaction without being prompted. 


\section{Box 2: Rumours surrounding the IUD}

- Can cause heart disease or heart attack

- Can lead to abdominal distension - one person even thought the IUD in causing abdominal distension can then cause fibroids ..."Is this not the same rubber which gives fibroids? Because the way the rubber makes your abdomen big...I hear fibroid also makes your abdomen big."

- Can cause infertility

- Causes offensive discharge

- Can cause disease

- Can cause irritation of the genital area

- Can lead to painful intercourse

- Can shift (become displaced), resulting in pregnancy

- Can fail and one can get pregnant even with the IUD in place. In such instances the baby may be born with it

- Can burn the womb

\section{Advantages of the IUD}

A few FGD participants that had heard or seen the IUD echoed some positive attributes to the method. They stressed that the IUD is effective and easily reversible (more effective than the pill because one could forget to take it), and they had used it before and there was no reason for alarm.

Providers themselves generally view the IUD positively in the sense that it is the most costeffective of all methods; it is convenient and non-hormonal with less systemic side effects.

Almost all trainers, policy makers and program managers interviewed were of the opinion that the IUD is a useful family planning method. One program manager stated: "The IUD has a major role to play because it is a bridge between the permanent methods and the hormonal." She explained that because one can have it for many years without any problems, if one is unable to make the decision for permanent method they could use the IUD.

\section{Eligibility criteria}

The 1999 Ghana National Reproductive Health Services Protocol (NRHSP) outlines the eligibility and non-eligibility criteria for the different family planning methods and also gives instructions to be followed by the service provider (see Box 3 ). The eligibility and non-eligibility criteria for use of the IUD state that:

- All women are eligible for the IUD (Copper T); however, it is not the first choice method for nulliparous women, particularly adolescents. 
- Pregnant women, women with unexplained vaginal bleeding (before evaluation), cancer or reproductive tract infections, or reported allergy to copper are absolutely ineligible for the IUD.

- Women with past history of ectopic pregnancy, increased risk of STIs including multiple sexual partners, complete expulsion of hydatidiform mole, anaemia, uterine fibroids, valvular heart disease and those that are HIV-positive are to be considered relatively noneligible for the IUD.

\section{BOX 3: History checklist for IUD Users: Service Provider's Instructions}

- It is advisable not to insert an IUD until six to eight weeks postpartum, unless the provider has been trained for post partum insertion;

- Client can have an IUD inserted if there is: no heavy bleeding and no sign of infection upon pelvic examination;

- If the client is not pregnant, the IUD may be inserted at any time during the menstrual cycle. If the provider is unsure of pregnancy, but has no pregnancy testing option, give a barrier method and reexamine four week later;

- If the client has had severe or repeated pelvic infections, treat client and partner(s), as appropriate. If client desires more children, do not insert an IUD. Help the client make an informed choice of another effective contraceptive method;

- Over the past three months, if the client has had any abnormally heavy periods, bleeding between periods or after intercourse, the provider should evaluate client by history and during pelvic exam and refer, as appropriate;

- If the client considers her bleeding during periods to be unusually heavy or often experiences severe menstrual pains, the provider should encourage the client to make an informed choice of another effective method;

- If the client or her partner has other sex partner(s) outside the relationship, in addition to the IUD the provider should encourage the client to use condoms to protect her against STI/HIVIAIDS;

- If the client is at risk of STI, the provider should help the client to make an informed choice of another effective method(s) which also protects against STI;

- If the client has ever had an ectopic pregnancy, the provider should counsel the client to use a combined oral contraceptive every day. If the client cannot or will not consistently use COC or another reliable method, high dose progestin-releasing and copper IUD provide 50 percent protection against ectopic pregnancy and are safe to use;

- If the client has severe anaemia on general examination, counsel and consider another method

- If the client has any ulcers and sores, treat or refer. Do not insert an IUD until all genital infections are cured. Encourage use of condoms and/or spermicides to protect against STI/HIVIAIDS; and

- If the client has an inflamed vaginal wall and a discharge in the vagina, treat and refer. Do not insert until an IUD until all genital infections are cured. Help the client choose another method.

Source: MOH 1999 National Reproductive Health Service Protocols. Republic of Ghana, Ministry of Health January 1999

The NRHSP also emphasizes that the IUD is not the first choice method for HIV-positive women, and that the condom should be added to all methods. 
When asked about which category of women are eligible for the IUD, most providers said they would give the IUD only to women who have delivered before and to faithfully married couples or clients with single partners. Other categories of clients mentioned included women with normal menstrual flow, those who want long-term contraception but not sterilization, any woman who chooses the IUD, and women who want to stop child bearing. Most providers frequently mentioned the category of nulliparous women as non-eligible. Certainly, some of the providers' views are the opposite of what the NRHSP recommend. Table 8 compares the providers' views and the NRHSP eligibility and non-eligibility criteria.

\section{Table 8: A Comparison of NRHSP on eligibility for the IUD and providers' views}

\begin{tabular}{|l|l|l|}
\hline $\begin{array}{l}\text { National RH Service Protocol } \\
\text { eligibility \& non-eligibility } \\
\text { criteria }\end{array}$ & Providers' views & $\begin{array}{l}\text { Providers' reasons for } \\
\text { non-eligibility }\end{array}$ \\
\hline $\begin{array}{l}\text { All women are eligible for the IUD } \\
\text { (Copper T), but for nulliparous } \\
\text { women, particularly adolescents, } \\
\text { the IUD is not the first choice. }\end{array}$ & $\begin{array}{l}\text { All women are eligible for the IUD, } \\
\text { except adolescents who are } \\
\text { nulliparous. }\end{array}$ & $\begin{array}{l}\text { Depth of uterus would } \\
\text { not be wide for insertion } \\
\text { Possibility of causing } \\
\text { infertility }\end{array}$ \\
\hline $\begin{array}{l}\text { Women with pregnancy, } \\
\text { unexplained vaginal bleeding } \\
\text { (before evaluation), cancer of the } \\
\text { reproductive tract infections, or } \\
\text { allergy to copper are absolutely } \\
\text { non-eligible for the IUD. }\end{array}$ & $\begin{array}{l}\text { Women who are allergic to } \\
\text { copper are ineligible for the IUD. }\end{array}$ & Reaction to copper \\
\hline $\begin{array}{l}\text { Women with a past history of } \\
\text { ectopic pregnancy, increased risk } \\
\text { of STIs including multiple sexual } \\
\text { partners, complete expulsion of } \\
\text { hydatidiform mole, anaemia, } \\
\text { uterine fibroids, valvular heart } \\
\text { disease and those that are HIV- } \\
\text { positive are relatively non-eligible } \\
\text { for the IUD. }\end{array}$ & $\begin{array}{l}\text { Women with multiple sexual } \\
\text { partners are non-eligible for the } \\
\text { IUD. } \\
\text { Women with complications such } \\
\text { as fibroids, history of ectopic } \\
\text { pregnancy and previous } \\
\text { caesarean section are non- } \\
\text { eligible for the IUD. } \\
\text { Women with untreated vaginal } \\
\text { discharges, and STI/HIV are non- } \\
\text { eligible for the IUD. }\end{array}$ & $\begin{array}{l}\text { Sounding of the uterus } \\
\text { will not be possible and } \\
\text { perforation can occur } \\
\text { during insertion }\end{array}$ \\
\hline $\begin{array}{l}\text { Spread of infection } \\
\text { Spread of infection }\end{array}$ \\
\hline
\end{tabular}

When asked about the timing for IUD insertion all providers said they would insert the IUD when clients were in their menses for ease of insertion and exclusion of pregnancy. This finding was confirmed during simulated client interactions with providers. They were advised to return during menses for insertion.

It was common for providers to discourage the use of the IUD by nulliparous clients. In 22 of the 46 interactions where a nulliparous profile were presented, simulated clients were told they could not use the IUD. However, in almost all simulated interactions, clients did not have to ask the providers about the IUD, providers spontaneously discussed and explained about it. Reasons given for refusal included fear of attributing possible future infertility to IUD use and an 
assumption that nulliparous women have multiple partners and therefore are more likely to be at risk of infections. The IUD was also discouraged in three interactions involving older simulated clients because they were more than 35 years old and wanted to space child bearing. In one instance the simulated client was told, "You are already 35 and you want to space but the IUD is for 10 years; by the time you remove it you will be in your menopause." For this reason, a shortterm method (i.e. the pill) was recommended.

The majority of providers interviewed said they would recommend the IUD to their friends because it is non-hormonal, users have menses every month, and it is a safe and reversible longterm method. A few providers who stated that they would not recommend the IUD to a friend expressed concerns about heavy and prolonged bleeding which can lead to death. About half of the providers said they would use the IUD themselves. Those who would not use it cited reasons such as having unfaithful partners, preference for natural family planning and ineffectiveness of the IUD.

\section{Information exchange with simulated clients}

Simulated client visits revealed that providers mentioned a range of methods during all interactions. The IUD was mentioned in almost all interactions (147/159) and spontaneously mentioned in 123 of these instances. In 30 of the interactions, the SCs felt that providers had over-emphasized some methods, particularly the pill, condom, injection and Norplant. This practice was common in interactions that presented a nulliparous profile. Permanent methods were rarely mentioned.

Contraceptive samples were used as a visual aid in over half of all the interactions. The IUD sample was given to simulated clients in 87 of 159 interactions. Flip charts and pamphlets were used in one-third of the interactions. Sketches, questionnaire cards and improvised models were also sometimes used.

Providers nearly always asked the simulated client about their method preference (133/159). And when the SCs expressed interest in the IUD, the providers' responses varied. In 87 of 159 interactions the providers said it was okay and in 28 of 159 the providers did not like the method choice.

Providers discussed the long-term use of the IUD; most providers stated that the IUD could be used for a period of 10 years. In 12/159 interactions duration of use was not mentioned at all. However, several of the providers did not mention that the IUD is an easily reversible method.

Advantages of the IUD were mentioned in 61 percent $(97 / 159)$ of the instances. The frequently mentioned advantages include long-term (90), effective (60), easy to use (59), and quick return to fertility (61). The providers also mentioned that the IUD does not "mix with blood."

Disadvantages were mentioned in 88 of the interactions. The commonly mentioned ones include irregular or heavy menstrual bleeding, abdominal cramping, and pain during insertion and removal. None of the interactions included a discussion on STI/HIV. 


\section{Dual protection and concerns about transmission of STI/HIV}

Almost all the participants in the FGDs had heard of STIs. The most frequently mentioned were HIV and gonorrhoea, and occasionally syphilis. Regarding their opinion on whether the IUD could protect against STIs, participants said they were aware the IUD does not protect against these diseases. A few respondents had the misconception that the injectable would protect against diseases as well (Box 4), but many felt the condom offered the best protection.

They had knowledge of both the male and female condom. Participants in one group cited a particular chemical store where both female and male condoms had been packaged as a set for 2000 cedis (US\$ $0.25^{1}$ ), which they thought was quite affordable.

Box 4: Injection prevents disease

"The nurses said the injection can protect us from syphilis but not AIDS."

"The loop can give diseases but the injection protects us against diseases."

All providers said they would treat the STI before giving the IUD. When asked whether they would recommend the IUD to an HIV-positive client, all except one provider would not give the IUD. Instead they would counsel the client and recommend another method.

When asked what they worried most about during insertion of the IUD, most providers expressed fear about perforation of the client's uterus (24/35) as compared to concerns about infecting themselves or the client (6/35). When asked specifically about fear of being infected with HIV during insertion, about a third said they were concerned because the gloves could not be trusted; the disease is infectious and has no cure. Those who did not worry said they used sterile gloves and proper decontamination procedures.

Contrary to this opinion some program managers and trainers mentioned that providers were not giving the service mainly because of the fear of personal infection with HIV (Box 5).

\section{Method preference}

Regarding their opinion about shifting preferences, participants mentioned that they were not aware of this observation. They however suggested that the many side effects and rumours as well as fear of the method (product) could partly explain the observed shifting preferences. Participants also said that the fact that the IUD does not protect one from STI could be a possible reason for preference of other methods (see Box 6).

A little over half of the providers were of the opinion that clients were switching from the IUD to other methods. Reasons cited include infections, misconceptions and the desire to try out new

\footnotetext{
${ }^{1}$ IUS\$ was equivalent to 8,200 cedis at the time of the study
}

\section{Box 5: Program Manager View}

"A lot of the staff are afraid of inserting the IUD because of the HIVIAIDS... Since they are not very sure of the infection prevention measures available, they don't want to go into the pelvis of the woman, and therefore discourage the women from accepting that method as they don't want to contaminate themselves."

\section{Box 6: Preference for other methods}

"The condom is easy to use, you just get up and wear it. On the other hand the advent of AIDS makes wearing the IUD difficult since it only prevents pregnancy and not diseases thus one needs a condom in addition. This will make it double and more expensive." 
methods such as Norplant. In comparison to other long-term methods such as the implants and the injectable, providers said that the IUD rarely featured as a first choice method among clients seeking long-term methods.

Most program managers and trainers were of the opinion that IUD use had slowed down considerably. They gave several reasons for the decline in IUD use, including the following:

- Poor image and misconceptions about the product. They suggested that there has been limited effort at dispelling rumours, and promoting the method through advertisements as is done for other products.

"My opinion really is that it has not been given the publicity it deserves."

"You see these adverts also have a lot of impact. Injectables have been well advertised so that could be the reason."

"I think there is a shift from IUD towards the injectables and so the acceptor rate is falling. We haven't really done any study to find out but probably clients are shifting to other methods which maybe they find safe. There are still these myths and mysteries about IUDs and I think they spread it from community to community and maybe the midwives are not also doing much to encourage users."

- Risk of infection to both clients and providers, with specific reference to HIV:

"I think if they don't do something about the infection prevention measures the staff will not have the confidence to do it and if the staff don't have the confidence to do it they are not going to encourage the people."

"We do know that many sexually active people do not have single partners, and because of the risk of infection many people do not want to use the IUD. Particularly with the onset of HIV, many people want to protect themselves and perhaps the way to go may be the use of condoms and that may contribute to the decline in the use of the IUD."

"I have problems because our women tend to have infections too much. The midwives tell you that maybe if you have 10 deliveries as much as 8 of them will be discharging (referring to vaginal discharge)... and people don't seek help about these things, making them more susceptible to HIV."

- Provider bias and ignorance. One program manager explained:

"I think that a lot of us health workers are illiterates when it comes to family planning. We don't know much about family planning and therefore the information that we give to clients is nothing that we can talk about because a health worker can ask the client 'do you want to die, why did you go in for IUD?' Yes! People say it. 
Health workers! And when users have problems, health workers will tell them it's because of the IUD."

- Complexity of service provision. This has to do with the many requirements necessary for IUD insertion such as the need for sterilization equipment and pelvic examinations. Some of the interviewees had this to say:

"You need the clinic setting which makes IUD insertion inconvenient in the field.

Unlike the injectable, which does not require too much sterilization equipment."

"According to the National Policy and Standards, only midwives are trained to insert the IUD because of the need to sound the uterus."

- The type of IUD available (only Copper T380A) was also suggested as responsible for declining use since it has been associated with abnormal discharge. As one respondent explained:

"I strongly believe so because people had IUD insertion for more than 20-25 years when it was the Lippes and didn't have much problem. But now it is not so. I have heard a few people complaining about some peculiar discharges with the copper ones, but I haven't seen any. Some service providers are saying that they think it is the IUD that is bringing about that type of discharge."

- Training of service providers. A program manager said that, in her opinion, there appears to be a closer collaboration between the nurses and midwives trained for Norplant insertion because they are trained together as a team. With the IUD, however, collaboration between the public health nurse and midwives is sometimes poor because only midwives are trained. Furthermore the training methodology for Norplant, in their opinion, has contributed to its success.

"The success with the implant has been that there has been training of midwives and nurses apart from doctors in insertion and removal, and that has increased access and the demand is being met more in those places."

- Method preference: it was suggested that women do not like the IUD and even those who use it have shifted to other methods.

"The women themselves are rejecting it, so why do we want to force them?"

"Anecdotally because we go through service providers, we have heard that Norplant for example is trying to take some of the IUD customers. Most of these customers opted for IUD because they didn't like the hormone but then they also like the Norplant because they don't have to go and see the service provider too often. Again it does not have the associated infections and the heavy bleedings. This has to be backed scientifically of course." 


\title{
Contextual Issues
}

\author{
Service Delivery System
}

\section{Training}

Although there are several institutions involved in family planning training, training in IUD insertion is limited to only a few institutions: the Ghana Registered Midwives Association (GRMA); the Public Health Nursing School (PHNS); Accra, and three Midwifery schools in Kumasi, Koforidua and Tamale. GRMA has identified three facilities in the country as training centres for the IUD. The other institutions run a four-week comprehensive family planning course with emphasis on the IUD four times a year. The course is sponsored by the UNFPA through the $\mathrm{MOH} / \mathrm{GHS}$. Table 9 shows the focus of training activities of the institutions.

All 35 providers interviewed said they had had some sort of exposure to family planning training. However, only 7 of them had attended the four-week comprehensive Family Planning course that places emphasis on the IUD. Out of the seven who had had the training, one had not done any insertions in the past year because of lack of demand for the method. As explained by the provider: "The people here are not interested in IUD. They all prefer the injectable. Their minds are already made up before they come to the clinic." Fifteen out of thirty five providers interviewed had not done any insertions in the past year. Though a few said they do not need any training, many expressed the desire for refresher training to update their knowledge about the IUD.

Table 9: Family Planning Training Institutions in Ghana - Activities and Focus

\begin{tabular}{|l|l|l|l|}
\hline Institution & Main focus & Specific training activities & IUD focus \\
\hline $\begin{array}{l}\text { Engender- } \\
\text { health }\end{array}$ & $\begin{array}{l}\text { Family } \\
\text { planning }\end{array}$ & $\begin{array}{l}\text { Long Term surgical methods for doctors \& } \\
\text { nurses } \\
\text { Infection prevention } \\
\text { Facilitating supervision }\end{array}$ & None \\
\hline $\begin{array}{l}\text { PRIME/ } \\
\text { INTRAH }\end{array}$ & $\begin{array}{l}\text { Safe } \\
\text { motherhood }\end{array}$ & Safe motherhood for doctors \& midwives & Limited to counselling \\
\hline JHPIEGO & $\begin{array}{l}\text { Clinical skills } \\
\text { training in } \\
\text { safe } \\
\text { motherhood }\end{array}$ & $\begin{array}{l}\text { Pre-service midwifery training } \\
\text { Cervical cancer prevention } \\
\text { Infection prevention }\end{array}$ & Limited \\
\hline $\begin{array}{l}\text { Midwifery } \\
\text { Schools }\end{array}$ & $\begin{array}{l}\text { General } \\
\text { midwifery }\end{array}$ & $\begin{array}{l}\text { Pre-service midwifery training } \\
\text { One month comprehensive FP course } \\
\text { with emphasis on IUD*-- nurses \& } \\
\text { midwives }\end{array}$ & Major \\
\hline $\begin{array}{l}\text { Public } \\
\text { Health } \\
\text { Nursing } \\
\text { School }\end{array}$ & $\begin{array}{l}\text { Preventive } \\
\text { Health } \\
\text { Services }\end{array}$ & $\begin{array}{l}\text { Pre-service preventive health services - } \\
\text { public health nurses } \\
\text { One month comprehensive FP course } \\
\text { with emphasis on IUD }\end{array}$ & Limited \\
\hline GRMA & $\begin{array}{l}\text { Safe } \\
\text { motherhood } \\
\text { \& family } \\
\text { planning }\end{array}$ & $\begin{array}{l}\text { Safe motherhood } \\
\text { FP } \\
\text { Infection prevention } \\
\text { STI/HIVIAIDS }\end{array}$ & $\begin{array}{l}\text { Major } \\
\text { (For private midwives) }\end{array}$ \\
\hline
\end{tabular}

* This program is run at three institutions: Kumasi, Koforidua and Tamale. 


\section{Supplies and equipment}

A 1997 Ghana Situation Analysis (GSA) study of the family planning covering 313 Service Delivery Points (SDP) across the country shows that only 56 percent of the SDP were able to offer the IUD. Supplies were available at 91 percent of these SDP and only 11 percent reported stock-out during the last six months.

In this study, none of the facilities in the Greater Accra region reported any shortage of the IUD or related expendables (gauze, disinfectant, gloves) in the past year. Out of the eight facilities visited in the Volta Region, only three offer IUD services and only one of these had had shortages in the past year. The remaining five facilities do not provide IUD services because of the absence of trained personnel at four facilities and the religious inclinations of a provider at one facility. In the Eastern Region all facilities visited provide IUD services and two had shortages in the past year. The Copper T380A is the only type procured and distributed by the National FP programme.

\section{Cost}

Family planning services in Ghana are not free to clients. In view of this the $\mathrm{MOH}$ has standardized prices for the product. Pricing for related expendables is the responsibility of individual service delivery points. Simulated clients reported that they were asked to pay $1000-$ 20,000 Cedis to have an IUD inserted in public facilities, with an average cost of 10,000 Cedis (about US\$1.22). At the private facilities the fee ranged from 30,000 to as high as 200000 Cedis.

\section{Policy}

According to the National Population Council (NPC) and the Ghana Health Service (GHS) the current national policy is that family planning methods should be made accessible and affordable to all. The policy also embraces the concept of quality of care and emphasizes giving information to individuals to enable them to make informed choices. The policy direction is for the public to have a wide range of choices with the public sector concentrating on long-term methods whilst the private sector deals with the short-term methods. However, in the context of STI/HIV and adolescent health needs, the actual practice is for both sectors (private and public) to promote condom use and dual protection.

Regarding the IUD specifically, the GHS position from the interviews conducted is that it is a method that is well tolerated by many women, and that it is also long-term and cost effective. The risk of infection is not high for women in monogamous relationships, but it increases if the partner is unfaithful. Thus, the GHS would not discourage the use of the IUD, but then dual protection has to be promoted as well. One program manager interviewed, however, challenged this position:

"I feel it's very democratic to have a full range of methods if you can afford it, but if you have limited resources that should also influence your choice. So we have to look at how much that extra method is going to cost per intercourse and find out whether it is cost effective. So it depends on how much money you have but personally I think we can minimize the range... What is the trade off of IUD? Is it just because it is cheaper?" 


\section{Demand generation}

When FGD participants were asked the question "should the IUD be promoted as a family planning method?" Most of them said that though they would not use it themselves, they would not mind it being recommended, as it may be useful for others.

In response to the same question, program managers and providers proposed targeted information on the IUD through electronic media. They specifically mentioned 'emaa nkomo,' a talk show program on issues affecting women. They also proposed the intensification of public education using different strategies such as male involvement, the testimony of satisfied clients, and IEC materials such as leaflets and posters. Other actions recommended include training of untrained health personnel, introduction of postpartum IUD insertion, and ensuring availability of insertion kits.

Program managers from two key social marketing agencies were asked whether they had specific activity shift towards or against any particular method. Overall, the discussions revealed that none of these agencies had a deliberate activity shift towards or against any particular family planning method. Rather both agencies had broad and practical shifts shaped by the nature of their activities.

For instance, one social marketing agency has shifted from providing family planning to the general population to targeting youth with reproductive health services and therefore focuses on condom and pill services. Furthermore, Norplant and the injectable are considered convenient and cheaper to administer in the field because trained field assistants from mobile clinics provide them; this offers greater possibility of reaching more people than the IUD. Program managers also admitted that they were limited in their efforts to promote the IUD in particular. The IUD was also considered a difficult method to distribute in the community due to service complexities.

Even so, one source from a distributing organisation was of the view that the IUD will always have a place on the Ghanaian market because it is an effective, long-term non-hormonal method, and there will always be clients who prefer it. However they stated that there would be a continuous decline in its demand due to other competing products on the market. This competition, especially from Norplant, needs to be addressed. Thus, the organization's opinion is that until a survey is done to find out what the "hot buttons" for the IUD are, they are reluctant to go out and create a market for this product.

Another major limitation mentioned was that the IUD, unlike other products, is unbranded, yet in social marketing the need to identify with "your" product is overriding. Thus, it is considered difficult to disseminate information on the use of the IUD or even to carry out targeted market studies. For instance, condoms and injectables have been promoted because they are branded. As stated by one program manager, it then becomes "ours" and can therefore be easily monitored. Examples of such brand names mentioned include the "Famplan" and the "Champion" condom. 


\section{Discussion}

\section{The role of community perceptions on the use of the IUD}

These findings identify several community perceptions and misperceptions about the IUD that seem to contribute to its declining trends in Ghana. The perceptions, which were mostly negative, were mainly from potential clients. Many of these clients, though, had never used or even seen the IUD, but had heard many rumours and speculation about it. Rumours about the IUD therefore discourage its use and it is important that efforts are made to dispel them. The few respondents who had ever used the method had some positive things to say. Hence familiarity with the product may help remove some of the negative attitudes.

The design of the product itself contributed to the negative image, inducing fear and apprehension in some women, as seen from the comments made by the focus group discussion participants. The design gives credence to the speculation that it could cause harm to the body.

The side effect of excessive bleeding and weight loss associated with use of the IUD is a real disincentive. This may contribute significantly to the shifting client preferences away from the IUD to other methods such as the injectable, which coincidentally has the side effect of amenorrhoea and proven weight gain. Information from the focus group discussions show that socially, weight loss is associated with unattractiveness and weight gain with beauty. This belief promotes the increased use of the injectable against the IUD. There appears to be real competition from the injectable, which has the added advantage of having a preferred route of administration. The injectable is also popular because it is thought to be medicinal because of its mode of administration, and the fact that it gets into the blood circulation. On the contrary, the IUD does not "mix with the blood" as stated by a focus group participant.

The concern expressed about the IUD irritating partners featured prominently and it justifies an exploration of the subject, probably through interviews with men who have partners with IUDs.

\section{Provider attitudes}

Contrary to the general belief that providers' bias against the IUD may contribute to the decline in use, these findings show that providers generally have a favourable attitude towards the IUD. They offer it as one of the options to clients and actually make the attempt to dispel associated rumours. Moreover, the assertion made by program managers/trainers that fear of contamination during IUD insertion could prevent the providers from recommending the method, is not correct. Providers' fears had mainly to do with harm to the client during insertion, rather than to themselves. This suggests that providers may not be confident of their insertion skills. If indeed providers worry about having to conduct a vaginal examination before inserting the IUD, then what about other similar situations, such as delivery.

Provider bias was found to be in relation to parity. Providers admitted that they would not give the IUD to nulliparous women, including adolescents. This practice is contrary to the National 
Reproductive Health Protocols which state that: "The IUD (Copper T) is eligible for all women, but for nulliparous women particularly adolescents, the IUD is not the first choice." Thus, providers are not exactly acting within the guidelines, denying adolescents and nulliparous women access to a method that offers important advantages over other forms of contraception -it is non-hormonal and long-term, requires minimal compliance, and return to fertility is immediate.

The NRHSP guidelines categorically stated that pregnancy is an absolute contraindication for IUD use. This may explain why providers insisted on excluding pregnancy in simulated clients before providing the method.

The findings also show that providers give clients information about side effects of the method only if the client is eligible for it. No such information is given to non-eligible clients. According to the protocol, providers are expected to take a full history of the client before conducting a physical examination. However, in practice it appears that providers do not take the full history before recommending or discouraging the use of a method.

\section{Considerations for dual protection}

According to the national reproductive health service protocols, the IUD is not a first choice for HIV-positive clients. The use of the condom together with another family planning method is recommended. This position is also in accordance with WHO recommendations, which state that insertion of the IUD in an HIV-infected woman or one who is at high risk of infection is not usually recommended. However a study in Kenya has raised questions about these guidelines (Sinei et al 1998). The study found that there were no more overall complications following insertion in HIV-infected women than in uninfected women. The National STI/HIV control policy document is however silent on the use of IUDs in HIV-positive patients.

It is also important to examine the impact of the accelerated promotion of the condom in the context of STI/HIV/AIDS control on the information provided on other contraceptive methods, including the IUD. This is because respondents raised concerns about the cost implications of dual protection. Given that the condom is not as effective a contraceptive and a back up is essential, there is the need to educate prospective clients on the importance of dual protection.

In promoting the condom, there is the need for education on the proper use of male and female condoms. Pairing the two for sale by some chemical shop owners, as mentioned, could give a wrong message that the two could be used simultaneously. This practice should be discouraged.

\section{Service Delivery System Barriers}

Several barriers at the service delivery level have been identified that may restrict clients access to IUD. These include training, cost of the IUD, demand generation/promotion, logistics and supplies. 


\section{Training}

IUD pre-service training for nurses and midwives appears to be inadequate as it is limited to general training and most providers may not have the opportunity to perform any insertions because the IUD is a low case load method. Some providers who said that they could not provide the service because they had not been adequately trained confirm this assertion. IUD insertion is a skill requiring practice, thus even for those trained, a low caseload at the service delivery point could result in many losing the skill.

There may be the need to revise the policy requirement that only trained midwives can insert the IUD. This requirement blocks nurses who qualify without having done midwifery, and are therefore not allowed to perform pelvic examinations. This includes male nurses and nurses specialised in public health. Those who had attended family planning training said they had no confidence inserting the IUD because they had not been allowed to make any practical insertion during the course since they were not midwives. Ultimately, this limits access to the method.

The information on providers' experience, which this study tried to obtain based on the number of insertions performed was distorted because most of the providers reported on insertions by the facility and not about their personal experience. It is important that providers sign for insertions that they have personally done. This would be useful in cases of a clinical audit (e.g. evaluation, tracing responsibility for complications) and for improving record keeping. What is clear, however, is the fact that less than a quarter of providers interviewed had attended the four-week comprehensive training for the IUD, which from interviews appears to be the main in-service course, and which offers the opportunity to acquire practical insertion skills.

\section{Cost of the IUD}

The average cost of having an IUD inserted in the public facilities was found to be 10,000 Cedis (about US\$1.22). This amount, when compared to the method's 10-year lifespan, is cost effective. In contrast, the injectable costs about 2000 cedis, but has to be administered four times a year, giving a total cost of about 80,000 Cedis for a 10 -year period. Thus in real terms the cost of the IUD should not be a barrier to use. However, it is possible that prospective clients may find it easier paying 2,000 Cedis upfront than 10,000 Cedis, making the IUD more expensive in that instance. It is also not clear how many couples consider the cost of contraception beyond the time of purchase (GSA 1997). Also, the price range of 30,000 to 200,000 Cedis reported from private facilities raises some concern and may be a real barrier to access.

\section{Demand generation and marketing}

The general impression from the discussions is that family planning service agencies have more experience in promoting short-term than long-term methods, thus a significant proportion of their time is spent providing these methods. This is worsened by the complexity of service provision in the case of the IUD in particular, as well as the unbranded nature of the product. The advent of HIV seems to have aggravated the problem by giving impetus to condom promotion. Even agencies such as the Ghana Health Service, who had the original responsibility for promoting the IUD, have intensified their efforts in condom promotion. To make the IUD attractive to 
prospective clients, it should be given equal attention. Both public and private sectors should do this. Branding the product may also improve marketing and promotion.

\section{Logistics and supplies}

Generally the facilities have adequate logistics and supplies, with only one facility reporting that they had not provided the service for a whole year due to shortage. 


\section{Conclusions and Recommendations}

The stagnating demand for the IUD as a family planning method can be said to be due to several factors. The main barriers impeding IUD use are rumours and misconceptions about the method, insufficient education about of the product (i.e. poor demand creation), and insufficient number of providers with practical experience.

It is important to do more than train providers to insert and remove the IUD; there is the need to encourage clients to use it as an option and to encourage providers to provide clear and adequate information about it. More specifically there is a need to:

- Intensify marketing of the IUD through the Ghana Life Choices Program and other social marketing agencies using multiple strategies including branding of the product, and the testimonies of satisfied clients to dispel rumours and demystify the product; and

- Improve provider confidence in IUD insertion skills through a hands-on training approach and create a critical mass of trained IUD providers.

The MOH should review the National Reproductive Health Service Protocols on who qualifies to insert and remove the IUD, and also clarify the eligibility criteria with regards to nulliparous and HIV-infected clients. The ministry and existing family planning service agencies should also address issues related to cost and provide public education on dual protection. Clients should be informed about the ease and cost-effectiveness of using the IUD; that it requires only one visit (plus check-up) in contrast to injections or the pill, which require routine visits.

A dissemination meeting held with stakeholders in November 2002 recommended the following strategies to improve the marketing and service delivery of the IUD:

\section{Marketing of the IUD}

- Improving product image: It was agreed that experiences from other countries on branding should be studied to inform the decision whether to brand or not. Additionally, activities should be based on the outcome of the ongoing Life Choices programme for family planning.

- Product packaging: It was recommended that the IUD should be pre-packed with other expendables such as gloves and gauze. This would help reduce price variations and avoid partial stock outs.

- Advertising: this should be actively done through the electronic media. Messages on the IUD should emphasize the positive attributes of the product and address the identified misconceptions.

- Target population: promotional campaigns should also target men since most of the fears or rumours that surround the IUD bring out the male concerns. 


\section{Improving Service Delivery}

- Personnel: All health cadres with the skill to conduct pelvic exams should be trained to insert the IUD. In-service training should include doctors.

- Follow up: Trainers should conduct bi-annual follow-ups. Furthermore, health managers should include the IUD in their routine supervision. Follow up activities should include capacity assessment as well.

- Attrition: Train more providers and encourage managers to maintain trained providers at sites where they would be useful.

- Refresher training should be regularized and conducted within three to five years after training.

\section{Supplies and Equipment}

- There is the need to procure more IUD insertion kits for the facilities. Additionally, models should be made available at all service delivery points. This will enable providers to practice and improve their insertion skills. 


\section{References}

Bhatia, JC \& J. Cleland 1995. "Self reported Symptoms of Gynecological Morbidity and their Treatment in South India". Studies in Family Planning 26: 203-216.

Brambila C. "Availability and Acceptability of IUDs in Guatemala". A Frontiers in Reproductive Health Diagnostic Study Proposal, December 1, 2001.

Costello MP; Chaves CM; Echavez CR; Encena J; \& OP. Pagulayan 1998 Integrating RTI Case Management within LGU Health Centers: An Intervention Study. Final Report submitted to the Asia and the Near East Operations Research and Technical Assistance Project. Family Planning Operations Research and Training Program. Population Council, Manila in Collaboration with the Department of Health. USAID contract No. DPE-C-00-90-0002-10. Strategies for Improving Family Planning Service Delivery.

Ghana Statistical Service 1997 Second Round Situation Analysis Study of Family Planning Service Delivery Point in Ghana. Ghana Statistical Service, November 1997.

Ghana Statistical Service \& Macro International 1999 Ghana Demographic \& Health Survey $\underline{1998}$

Huntington D.; \& SR. Schuler 1993. "The Simulated Client Method: Evaluating Client-Provider Interactions in Family Planning Programs". Studies in Family Planning, Volume 24, No. 3 May/June 1993.

Hoesni, RHM; Tan A; Tuladhar JT; effendi JS; Hadijanto B; \& P. Hartono 1995. Follow-up among IUD Acceptors of Java, Indonesia. Final Report of the Asia and the Near East Operations Research and Technical Assistance Project. Sub-contract No. CI94.31A.

Magadi, M.; Zulu E.; Ezeh A.; \& S. Curtis 2001. Contraceptive Use Dynamics in Kenya: Further Analysis of Demographic and Health Survey (DHS) Data. African Population and Health Research Center (APHRC) \& MEASURE Evaluation Project ORC Macro, Calverton, Maryland, USA

Ngom, P. 1994. "Women's Informal Communication about Family Planning in West Africa." A Dissertation in Demography submitted to the Faculties of the University of Pennsylvania in Partial Fulfilment of the Requirements of the Degree of Doctor of Philosophy.

Rutenberg N. \& S. C. Watkins 1997. "The Buzz Outside the Clinics: Conversations and Contraception in Nyanza Province, Kenya". In Studies in Family Planning, Volume 28 No. 4 December 1997 
Stanback J.; Omondi-Odhiambo; \& D. Omuondo 1995. Why has IUD use Slowed in Kenya: Qualitative Assessment of IUD Service Delivery in Kenya. A Report for Family Health International

Speizer S. I; Hotchkiss D. R.; Magnani R. J.; Huuard B; \& K. Nelson 1998. Do Family Planning Service Providers in Tanzania Unnecessarily Restrict Access to Contraceptive Methods? Tulane University, USA.

Sunei SK; Morrison CS; Sekadde-Kigondu C; Allen M; \& D. Kokonya. "Complications of Use of Intrauterine devices among HIV-1 Infected Women.” Lancet 1998; 351 (9111): 1238-41.

World Health Organization 1996. Improving Access to Quality of care in Family Planning: Medical Eligibility Criteria for contraceptive use. Geneva: World Health Organization, 1996) 132. 